\title{
Kombinasi Perlakuan Lumpur Laut dan Pupuk Kandang untuk Pertumbuhan dan Produksi Sawi Sendok (Brassica rapa L) pada Tanah Ultisol
}

\author{
Combination of Marine Mud and Manure Treatments for Growth and Yield of Spoon Mustard \\ (Brassica rapa L) in Ultisol Soil
}

\author{
Francina Matulessy, Meitty L. Hehanussa*, Yakobus Solarbesain
}

Program Studi Agroteknologi, Jurusan Budidaya Pertanian, Fakultas Pertanian, Universitas Pattimura

J1. Ir. M. Putuhena, Kampus Poka, Ambon 97233, Indonesia

*E-mail Penulis Korespondensi: meittyhehanussa@gmail.com

\begin{abstract}
Organic fertilizers have an important role in the success of vegetable cultivation. Marine mud contains a lot of nutrients and organic matter, so it is useful for improving degraded soils in the short term and a source of nitrogen and minerals (especially $\mathrm{Ca}$ and $\mathrm{Mg}$ ) in the long term. This study aimed to examine and explain the effect of doses of cow dung fertilizer and marine mud, for the growth and yield of spoon mustard (Brassica rapa L). This research was conducted at the Plastic House of the Faculty of Agriculture, Pattimura University, from June to August 2018. The experiment in this study was a factorial experiment in a completely randomized design with two factors. The first factor was sea mud from Tulehu Village (L) with 4 levels, namely: without sea mud (control), $100 \mathrm{~g}, 200 \mathrm{~g}$ and $300 \mathrm{~g}$ per $\mathrm{kg}$ of soil. The second factor was cow manure $(\mathrm{K})$ with 4 levels, namely: without cow manure (control), $5 \mathrm{~g}, 10 \mathrm{~g}$. and $15 \mathrm{~g}$ per $\mathrm{kg}$ of soil. The variables observed included plant height, leaf number, leaf area, plant biomass fresh weight, crown fresh and root fresh weight. Data were analyzed using Analysis of Variance (ANOVA) and further test using Duncan's test at 0.05 level. The results showed that the sea mud treatment had a very significant effect on the variables of plant height (3, 4 and 5 weeks after planting, WAP), leaf number (4 and 5 WAP), leaf area, plant biomass weight and plant crown weight, number of leaves ( 3 WAP) and root weight, but had no significant effect on plant height at age (1 and 2 $W A P)$, and number of leaves ( 1 and 2 WAP). The treatment of cow dung fertilizer had a very significant effect on the variables of plant height (2, 4 and 5 WAP), number of leaves ( 3 and 5 WAP), plant biomass weight and plant crown weight, a significant effect on plant height (3 WAP), leaf number (4 WAP), but had no significant effect on plant height $(1 \mathrm{WAP})$, leaf number ( 1 and $2 \mathrm{WAP}$ ), leaf area and root weight of plants. The interaction between the treatment of marine mud and cow manure gave a very significant effect on plant height (4 and 5 WAP), but there was no interaction on the other observation variables.
\end{abstract}

Keywords: cow manure, marine mud, 'spoon' mustard, Ultisol soil

\section{ABSTRAK}

Pupuk organik mempunyai peranan penting terhadap keberhasilan budidaya tanaman sayuran. Endapan lumpur laut banyak mengandung unsur hara dan bahan organik, sehingga bermanfaat untuk memperbaiki tanah-tanah terdegradasi untuk jangka pendek dan sumber nitrogen dan mineral (khususnya $\mathrm{Ca}$ dan $\mathrm{Mg}$ ) untuk jangka waktu panjang. Penelitian ini bertujuan untuk menguji dan menjelaskan pengaruh dosis pupuk kotoran sapi dan dosis lumpur laut untuk pertumbuhan dan produksi tanaman sawi sendok (Brassica rapa L). Penelitian ini dilaksanakan di Rumah Plastik Fakultas Pertanian, Universitas Pattimura dari bulan Juni sampai Agustus 2018. Percobaan dalam penelitian ini merupakan percobaan faktorial dalam Rancangan Acak Lengkap dengan dua faktor. Faktor pertama adlah lumpur laut (L) dari desa Tulehu dengan 4 taraf, yaitu: tanpa lumpur laut (kontrol), 100 g, $200 \mathrm{~g}$ dan $300 \mathrm{~g}$ per kg tanah. Faktor kedua adalah pupuk kotoran sapi (K) dengan 4 taraf, yaitu: tanpa pupuk kotoran sapi (kontrol), $5 \mathrm{~g}, 10 \mathrm{~g}$. dan $15 \mathrm{~g}$ per $\mathrm{kg}$ tanah. Variabel yang diamati meliputi tinggi tanaman, jumlah daun, luas daun, bobot segar biomassa tanaman, bobot segar tajuk tanaman dan bobot segar akar tanaman. Data dianalisis menggunakan Analisis of Varians (ANOVA) dan uji lanjut menggunakan uji Duncan pada taraf 0,05. Hasil penelitian menunjukkan bahwa perlakuan lumpur laut berpengaruh sangat nyata terhadap variable tinggi tanaman (3, 4 dan 5 minggu setelah tanam, MST), jumlah daun (4 dan 5 MST), luas daun, bobot biomassa tanaman dan bobot tajuk tanaman, berpengaruh nyata terhadap jumlah daun (3 MST) dan bobot akar tanaman, tetapi berpengaruh tidak nyata terhadap tinggi tanaman umur (1 dan 2 MST), dan jumlah daun (1 dan 2 MST). Perlakuan pupuk kotoran sapi berpengaruh sangat nyata terhadap variable tinggi tanaman (2, 4 dan 5 MST), jumlah daun (3 dan 5 MST), bobot biomassa tanaman dan bobot tajuk tanaman, berpengaruh nyata terhadap tinggi tanaman (3 MST), jumlah daun (4 MST), tetapi tidak berpengaruh nyata terhadap tinggi tanaman (1 MST), jumlah daun (1 dan 2 MST), luas daun dan bobot akar tanaman. Interaksi antara perlakuan lumpur laut dan 
pupuk kotoran sapi memberikan pengaruh sangat nyata terhadap tinggi tanaman (4 dan 5 MST), namun tidak ada interaksi pada variable pengamatan lainnya.

Kata kunci: lumpur laut, pupuk kotoran sapi, sawi sendok, tanah Ultisol.

\section{PENDAHULUAN}

Tanaman sawi sendok (Brassica rapa L) merupakan salah satu jenis sayuran yang digemari oleh masyarakat Indonesia. Banyak jenis makanan yang menggunakan daun sawi sebagai bahan makanan utama maupun sebagai pelengkap. Kurniadi (1996) menyatakan sawi sendok selain dikonsumsi sebagai sayuran juga dapat bermanfaat bagi kesehatan manusia, terutama yang mengkonsumsinya secara kontinyu. Sawi sendok dapat menghilangkan rasa gatal ditenggorokkan pada penderita batuk, penyembuh sakit kepala karena mengandung vitamin dan zat gizi yang penting bagi kesehatan manusia.

Berdasarkan data Badan Pusat Statistik, produksi sayuran sawi sendok di Indonesia mengalami fluktuasi pada tahun 2012, 2013 dan 2014, yaitu 594,91; 635,70; dan 602,40 ton per tahun (Badan Pusat Statistik

dan Direktorat Jenderal Hortikultura, 2015).

Produksi sawi tersebut dapat disebabkan oleh kesuburan tanah, sehingga diperlukan budidaya yang baik untuk memperbaiki kesuburan tanah sekaligus meningkatkan produksi sawi sendok.

Produksi sawi sendok tidak hanya bisa ditingkatkan melalui penambahan areal tanam, namun dapat juga melalui budidaya yang baik, yaitu pemeliharaan dan pemupukan yang tepat. Menurut Sutejo dan Kartasapoetra (2002) pupuk organik mempunyai fungsi yang penting yaitu dapat menggemburkan lapisan permukaan tanah (top soil), meningkatkan populasi jasad renik, daya serap dan daya simpan air, yang secara keseluruhan dapat meningkatkan kesuburan tanah. Bahan organik yang diberikan dapat berupa padatan maupun berupa cairan, namun tujuan utama penambahan bahan organik ke tanah-tanah marginal, seperti ultisol, adalah untuk memperbaiki sifat fisik, kimia dan biologi tanah tersebut. Pupuk organik tersebut adalah lumpur laut dan pupuk kotoran sapi.

Pupuk mempunyai peranan penting terhadap keberhasilan budidaya tanaman sayuran. Tanaman membutuhkan pupuk yang sesuai untuk memenuhi kebutuhan unsur-unsur hara agar dapat tumbuh serta berkembang dengan baik. Pemberian pupuk organik dapat menambah cadangan unsur hara di dalam tanah, memperbaiki struktur tanah dan menambah kandungan bahan organik tanah. Salah satunya adalah pupuk kotoran sapi yang berasal dari kandang ternak sapi. Pupuk ini bisa berupa kotoran padat (faeces) yang bercampur dengan sisa makanan maupun air kecing (urine), sehingga kualitas pupuk kotoran sapi beragam tergantung pada: 1) jenis, umur dan kesehatan ternak; 2) jenis, kadar dan jumlah pakan yang dikonsumsi; 3) jenis pekerjaan dan lamanya ternak bekerja; 4) lama dan kondisi penyimpanan serta 5) jumlah dan kandungan haranya.

Endapan lumpur laut banyak mengandung unsur hara dan bahan organik. Pemanfaatannya di negaranegara berkembang untuk memperbaiki tanah-tanah terdegradasi untuk jangka waktu pendek dan sumber nitrogen untuk jangka waktu panjang, juga sebagai sumber hara $\mathrm{Ca}$ dan $\mathrm{Mg}$ (Matulessy et al., 2015), walaupun kandungan unsur haranya lebih rendah dari pupuk komersial. Pemberian lumpur laut pada tanah marginal yang bersifat asam dimaksudkan sebagai usaha untuk memperbaiki kemasaman tanah, kapasitas tukar kation, kejenuhan basa dan dapat menetralisir asamasam organik. Penelitian yang dilakukan pada lahan gambut dengan pemberian lumpur laut dapat meningkatkan produksi kedele 8-12 \% (Suryadi, 1995; Matulessy et al., 2015).

Ultisol merupakan salah satu jenis tanah di Indonesia yang mempunyai sebaran luas, mencapai 45.794.000 ha atau sekitar 25\% dari total luas daratan Indonesia (Subagyo et al. 2004). Sebaran terluas terdapat di Kalimantan (21.938.000 ha), diikuti di Sumatera (9.469.000 ha), Maluku dan Papua (8.859.000 ha), Sulawesi (4.303.000 ha), Jawa (1.172.000 ha), dan Nusa Tenggara (53.000 ha). Tanah ini dapat dijumpai pada berbagai relief, mulai dari dataran hingga bergunung.

Kesuburan alami tanah ultisol umumnya terdapat pada horizon A yang tipis dengan kandungan bahan organik yang rendah. Unsur hara makro seperti fosfor dan kalium yang sering kahat, reaksi tanah masam hingga sangat masam, serta kejenuhan aluminium yang tinggi merupakan sifat-sifat tanah ultisol yang sering menghambat pertumbuhan tanaman. Kondisi tanah ultisol dapat diperbaiki dengan memberikan bahan organik. Menurut Endriani (2010) bahwa semakin tinggi bahan organik tanah total porositas semakin tinggi sehingga ketahanan penetrasi tanahpun semakin berkurang dan selanjutnya tanah tersebut dapat dimanfaatkan untuk proses budidaya tanaman.

Berdasarkan latar belakang di atas , maka tujuan penelitian ini adalah untuk menguji dan menjelaskan pengaruh dosis pupuk kotoran sapi dan dosis lumpur laut untuk pertumbuhan dan produksi tanaman sawi sendok (B. rapa $\mathrm{L})$.

\section{BAHAN DAN METODE}

\section{Waktu dan Tempat}

Penelitian ini dilaksanakan di rumah plastik Fakultas Pertanian, Universitas Pattimura, Ambon, pada bulan Juni sampai Agustus 2018. 


\section{Bahan dan Alat}

Bahan yang digunakan dalam penelitian ini adalah benih Sawi sendok. lumpur laut (L) dari desa Tulehu, tanah ultisol dari Dusun Telaga Kodok, pupuk kotoran sapi $(\mathrm{K})$ dan pupuk NPK. Alat yang digunakan adalah rak vertikultur, polybag ukuran $30 \times 30 \mathrm{~cm}$, meteran, timbangan, Leaf Area Meter (LAM), cangkul, gembor, handsprayer, kamera digital dan alat tulis serta alat-alat lain yang mendukung penelitian ini.

\section{Pelaksanaan Penelitian}

\section{Tahap persiapan, pesemaian dan penanaman bibit}

Percobaan dalam penelitian ini merupakan percobaan faktorial dalam Rancangan Acak Lengkap. Perlakuan ialah kombinasi dua faktor. Faktor pertama ialah lumpur laut (L) dari desa Tulehu dengan empat taraf, yaitu: (tanpa lumpur laut, 100, 200 dan 300 g per $\mathrm{kg}$ tanah). Faktor kedua ialah pupuk kotoran sapi (K) dengan empat taraf, yaitu: (tanpa pupuk kotoran sapi, 5, 10 dan $15 \mathrm{~g}$ per $\mathrm{kg}$ tanah).

Terdapat 16 kombinasi perlakuan dengan 3 kali ulangan, sehingga didapat 48 unit percobaan. Setiap kombinasi perlakuan terdiri dari 3 tanaman, dengan demikian jumlah seluruh tanaman pada penelitian ini adalah 144 tanaman.

Pesemaian benih dilakukan pada media persemaian yaitu, tanah dicampur dengan pupuk kompos organik untuk menghasilkan pertumbuhan bibit yang baik. Sebelum penanaman benih, media disiram terlebih dahulu dengan air agar kelembaban tanah terjaga. Setelah media persemaian siap, benih sawi sendok ditebar secara merata pada wadah persemaian, dan selanjutnya benih yang telah ditebar ditutup dengan media pesemaian. Perawatan pada benih tanaman sawi sendok seperti penyiraman dilakukan bila media terlihat kurang air. Pemeliharaan terus dilakukan sampai menjadi bibit dan telah memiliki 2-3 daun, selanjutnya siap dipindah tanamkan ke polybag ukuran $(30 \times 30 \mathrm{~cm})$ yang telah berisi media tanam untuk percobaan

Tanah yang digunakan untuk media penanaman diambil dari lahan di Dusun Telaga Kodok, Desa Hitu. Selanjutnya tanah dihancurkan dari bongkahan tanah agar tidak menggumpal, dan memisahkan tanah dari batuan kecil, akar tanaman dan kotoran lainnya. tindakan ini juga bertujuan untuk mengurangi serasah pada tanah dan mendapatkan tanah yang gembur. Lumpur laut dari Desa Tulehu diambil, dikeringanginkan selama kurang lebih 2 sampai 3 minggu. Lumpur laut kemudian diayak untuk memisahkan kotoran yang ada.

Tanah ditimbang dengan bobot $3,5 \mathrm{~kg}$ setiap polybag. Kemudian dicampur secara merata dengan lumpur laut dan pupuk kotoran sapi sesuai dengan perlakuan yang dicobakan dan selanjutnya dimasukkan dalam polybag

Pemberian label pada polybag dilakukan sebelum pemindahan bibit tanaman sawi sendok atau satu hari sebelum pemberian perlakuan. Pemberian label bertujuan untuk membedakan perlakuan yang diberikan pada tanaman sawi sendok. Tanah yang sudah dicampur dalam polybag disiram sampai mencapai kapasitas lapang dan dibiarkan semalaman.

Penanaman dan pemindahan tanaman sawi sendok dilakukan setelah bibit sudah memiliki 2-3 helai daun. Sebelum bibit dipindahkan, dilakukan penyiraman terlebih dahulu pada nampan pembibitan agar tanah menjadi gembur dan tanaman sawi sendok mudah dipindahkan. Pemindahan dilakukan dengan mencabut bibit secara hati-hati dari tempat pembibitan dengan tidak merusak akarnya kemudian langsung ditanam ke dalam polybag yang berisikan media perlakuan.

\section{Variabel Pengamatan}

Tinggi tanaman diukur mulai dari pangkal batang sampai ujung daun tertinggi. Pengukuran dilakukan 1 minggu setelah tanam atau 7 hari setelah tanam (HST) dan selanjutnya pengukuran tinggi tanaman dilakukan pada saat tanaman berumur $14,21,28$, dan 35 HST. Jumlah daun dihitung 1 minggu atau 7 hari setelah tanam bersamaan dengan pengukuran tinggi tanaman, dan selanjutnya pada 14, 21, 28 dan 35 HST.

Pengukuran luas daun dilakukan pada minggu terakhir atau setelah tanaman dipanen, yaitu dengan cara diambil 3 daun; dari daun bagian bawah, daun bagian tengah dan daun bagian atas. Pengukuran luas daun dilakukan dengan menggunakan alat Leaf Area Meter (LAM). Nilai luas daun dari ketiga daun contoh pada setiap perlakuan dijumlahkan, kemudian dibagi tiga guna mendapatkan nilai rataan dan selanjutnya dikalikan dengan jumlah daun umur 35 HST untuk mendapatkan total luas daun tanaman pada setiap perlakuan.

Penimbangan bobot segar biomassa tanaman dilakukan dengan mencabut tanaman secara hati-hati agar tanaman tidak rusak. Tanaman dibersihkan dengan air dari tanah tanah yang menempel, setelah itu tanaman dikering anginkan beberapa saat, kemudian ditimbang. Bobot segar tajuk tanaman dapat diamati pada saat tanaman dipanen dimana tanaman yang di panen dipotong tepat dipangkal batang untuk memisahkan dari akar, setelah itu akan ditimbang menggunakan timbangan/neraca. Pengamatan bobot segar akar dilakukan setelah panen, yaitu bersamaan dengan penimbangan bobot segar tajuk. Pengamatan ini dilakukan menggunakan timbangan/neraca.

\section{Analisis Data}

Data hasil pengamatan akan dianalisis dengan menggunakan Analysis of Varians dan akan dilakukan uji lanjut dengan menggunakan uji Duncan pada taraf 0,05 untuk mengetahui beda nyata antar perlakuan dengan menggunakan program SAS

\section{HASIL DAN PEMBAHASAN}

Hasil penelitian Kombinasi perlakuan lumpur laut dan pupuk kandang kotoran sapi terhadap pertumbuhan dan produksi sawi sendok (Brassica rapa L) di tanah ultisol dapat dilihat pada Tabel 1. 
Tabel 1. Rekapitulasi hasil analisis ragam kombinasi perlakuan lumpur laut dan pupuk kotoran sapi terhadap pertumbuhan dan produksi sawi sendok (Brassica rapa 1 ) di Tanah Ultisol

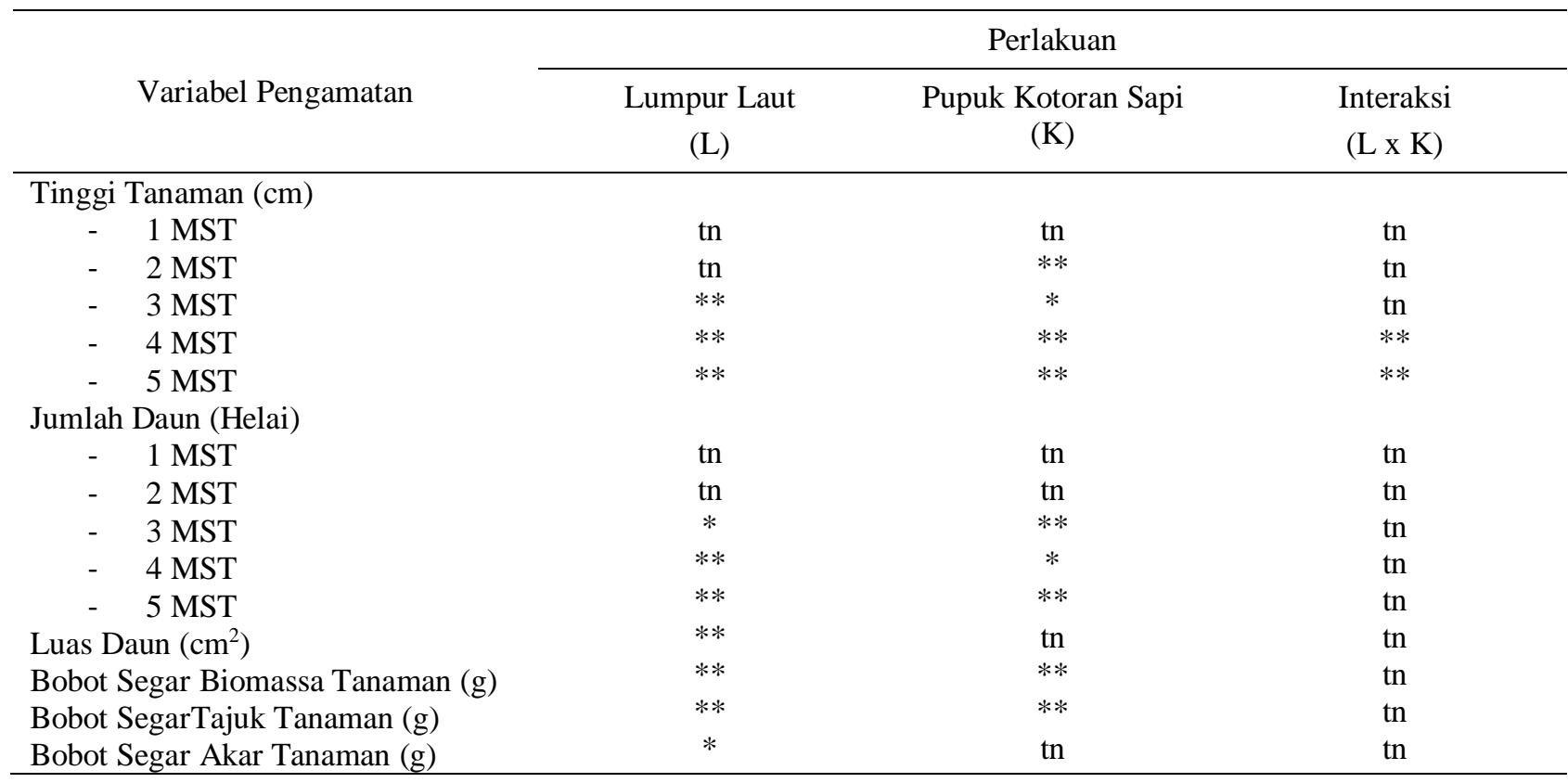

Keterangan : ** (berpengaruh sangat nyata); (berpengaruh nyata); tn (berpengaruh tidak nyata)

Perlakuan lumpur laut berpengaruh sangat nyata terhadap variabel tinggi tanaman (3, 4 dan 5 MST), jumlah daun (4 dan 5 MST ), luas daun, bobot biomassa tanaman dan bobot tajuk tanaman; berpengaruh nyata terhadap variabel jumlah daun umur 3 MST dan bobot akar tanaman, tetapi berpengaruh tidak nyata terhadap tinggi tanaman umur 1 dan 2 MST, dan jumlah daun umur 1 dan 2 MST (Tabel 1).

Perlakuan pupuk kotoran sapi berpengaruh sangat nyata terhadap variabel tinggi tanaman $(2,4$ dan 5 MST), jumlah daun (3 dan 5 MST), bobot biomassa tanaman dan bobot tajuk tanaman, berpengaruh nyata terhadap variabel tinggi tanaman (3 MST), jumlah daun (4 MST), tetapi tidak berpengaruh nyata terhadap variabel tinggi tanaman 1 MST, jumlah daun 1 dan 2 MST, luas daun dan bobot akar tanaman. Interaksi antara perlakuan lumpur laut dan pupuk kotoran sapi memberikan pengaruh sangat nyata pada variabel tinggi tanaman 4 dan 5 MST, namun tidak ada pengaruh interaksi terhadap variabel pengamatan lainnya.

\section{Tinggi Tanaman}

Tabel 2 menunjukkan bahwa tinggi tanaman pada umur 1 MST dan 2 MST tidak berbeda nyata, namun dapat dilihat bahwa perlakuan L2 memberikan nilai tertinggi pada kedua umur tanam tersebut, yaitu masingmasing dengan nilai $5,36 \mathrm{~cm}$ dan $12,50 \mathrm{~cm}$. Sedangkan nilai terendah ditunjukkan oleh perlakuan L0, yaitu dengan nilai $4,65 \mathrm{~cm}$ dan $11,06 \mathrm{~cm}$.

Tinggi tanaman umur tanam 3 MST berbeda nyata, dimana perlakuan lumpur laut L2 memberikan nilai tertinggi, yaitu $20,75 \mathrm{~cm}$, tidak berbeda nyata dengan perlakuan lumpur laut L3 dan L1, serta berbeda nyata dengan perlakuan L0 (kontrol) yang memberikan hasil terendah.

Tabel 2. Tinggi tanaman $(\mathrm{cm})$ pada berbagai perlakuan lumpur laut pada umur 1, 2 dan 3 MST

\begin{tabular}{cccc}
\hline Perlakuan & \multicolumn{3}{c}{ Tinggi tanaman $(\mathrm{cm})$} \\
\cline { 2 - 4 } & 1 MST & 2 MST & 3 MST \\
\hline L0 & 4,65 & 11,06 & $16,70 \mathrm{~b}$ \\
L1 & 5,23 & 12,00 & $19,17 \mathrm{a}$ \\
L2 & 5,36 & 12,50 & $20,75 \mathrm{a}$ \\
L3 & 4,97 & 11,85 & $20,03 \mathrm{a}$ \\
\hline Duncan $=$ & 0.535 & 1.090 & 1.943 \\
0.05 & 0.562 & 1.146 & 2.042 \\
& 0.580 & 1.182 & 2.106 \\
\hline
\end{tabular}

Keterangan: Angka-angka yang diikuti oleh huruf kecil yang tidak sama pada kolom yang sama menunjukkanberbeda nyata menurut uji duncan pada taraf uji 0,05

Tabel 3 menunjukkan bahwa tinggi tanaman umur 1 MST saling tidak berbeda nyata, namun perlakuan K2 memberikan nilai tertinggi, yaitu $5,20 \mathrm{~cm}$. Sedangkan nilai terendah ditunjukkanoleh perlakuan $\mathrm{K} 0$, yaitu dengan nilai $4,75 \mathrm{~cm}$.

Pada umur tanam 2 MST, perlakuan kotoran sapi K3 memberikan nilai tertinggi, yaitu $12,71 \mathrm{~cm}$ dan tidak berbeda nyata dengan perlakuan $\mathrm{K} 2$ dan $\mathrm{K} 1$; dan pada umur tanam 3 MST perlakuan kotoran sapi K2 memberikan nilai tertinggi, yaitu $20,20 \mathrm{~cm}$ dan tidak berbeda nyata dengan perlakuan kotoran sapi K3. 
Tabel 3. Tinggi tanaman $(\mathrm{cm})$ pada berbagai perlakuan kotoran sapi pada umur 1, 2 dan 3 MST

\begin{tabular}{cccc}
\hline Perlakuan & \multicolumn{3}{c}{ Tinggi tanaman $(\mathrm{cm})$} \\
\cline { 2 - 4 } & $1 \mathrm{MST}$ & $2 \mathrm{MST}$ & $3 \mathrm{MST}$ \\
\hline K0 & 4,75 & $10,64 \mathrm{~b}$ & $17,54 \mathrm{~b}$ \\
$\mathrm{~K} 1$ & 5,15 & $11,89 \mathrm{a}$ & $19,13 \mathrm{ab}$ \\
K2 & 5,20 & $12,17 \mathrm{a}$ & $20,20 \mathrm{a}$ \\
K3 & 5,11 & $12,71 \mathrm{a}$ & $19,79 \mathrm{a}$ \\
\hline Duncan $=$ & 0.535 & 1.090 & 1.943 \\
0.05 & 0.562 & 1.146 & 2.042 \\
& 0.580 & 1.182 & 2.106 \\
\hline
\end{tabular}

Keterangan: Angka-angka yang diikuti oleh huruf kecil yang tidak sama pada kolom yang sama menunjukkan berbeda nyata menurut uji duncan pada taraf uji 0,05

Tabel 4. Interaksi antara perlakuan lumpur laut dan pupuk kotoran sapi terhadap tinggi tanaman (cm) umur 4 MST

\begin{tabular}{|c|c|}
\hline Perlakuan & Rata-rata $(\mathrm{cm})$ \\
\hline L2K2 & $26,26 \mathrm{a}$ \\
\hline L3K1 & $24,93 \mathrm{ab}$ \\
\hline L2K1 & $24,46 \mathrm{ab}$ \\
\hline L3K2 & $24,13 \mathrm{ab}$ \\
\hline L2K3 & $24,10 \mathrm{ab}$ \\
\hline L1K3 & $23,86 \mathrm{ab}$ \\
\hline L3K3 & $23,86 \mathrm{ab}$ \\
\hline LOK3 & $23,66 \mathrm{abc}$ \\
\hline L2K0 & $23,10 \mathrm{bcd}$ \\
\hline L3K0 & $22,43 \mathrm{bcd}$ \\
\hline L1K2 & $22,36 \mathrm{bcd}$ \\
\hline L1K0 & 20,80 cde \\
\hline LOK2 & $20,66 \mathrm{de}$ \\
\hline L1K1 & $20,20 \mathrm{de}$ \\
\hline LOK1 & $19,20 \mathrm{e}$ \\
\hline LOK0 & $14,70 \mathrm{f}$ \\
\hline \multirow{3}{*}{$\begin{array}{c}\text { Duncan }= \\
0.05\end{array}$} & $\begin{array}{llllll}2.649 & 2.784 & 2.872 & 2.935 & 2.983 & 3.020\end{array}$ \\
\hline & $\begin{array}{llllll}3.050 & 3.075 & 3.095 & 3.113 & 3.128 & 3.140\end{array}$ \\
\hline & 3.1513 .1603 .168 \\
\hline
\end{tabular}

$\overline{\text { Keterangan: Angka-angka yang diikuti oleh huruf kecil yang }}$ tidak sama pada kolom yang sama menunjukkan berbeda nyata menurut uji Duncan pada taraf uji 0.05

Pada umur tanaman 4 MST, interaksi antara perlakuan lumpur laut dan pupuk kotoran sapi berpengaruh sangat nyata terhadap tinggi tanaman (Tabel 4). Pada uji Duncan terhadap tinggi tanaman 4 MST menunjukkanbawah perlakuan L2K2 (200 g L per $\mathrm{kg}$ tanah dan $10 \mathrm{~g} \mathrm{~K}$ per $\mathrm{kg}$ tanah) memberikan nilai tertinggi, yaitu $26,26 \mathrm{~cm}$. Sedangkan nilai terendah terdapat pada pengamatan tinggi tanaman umur 5 MST, ini ditunjukkanpada kombinasi perlakuan LOK0 (kontrol tanpat pemberian lumpur laut maupun pupuk kotoran sapi) dengan nilai $14,70 \mathrm{~cm}$.

Pada umur 5 MST, interaksi antara perlakuan lumpur laut dan pupuk kotoran sapi berpengaruh sangat nyata terhadap variabel tinggi tanaman (Tabel 5). Pada uji lanjut Duncan terhadap tinggi tanaman 5 MST menunjukkanbahwa kombinasi perlakuan L3K3 (300 g $\mathrm{L}$ per $\mathrm{kg}$ tanah dan $15 \mathrm{~g} \mathrm{~K}$ per $\mathrm{kg}$ tanah) memberikan nilai tertinggi, yaitu 29,46 cm. Sedangkan nilai terendah terdapat pada tinggi tanaman umur 5 MST; ini ditujukan pada kombinasi perlakuan LOK0 (kontrol tanpat pemberian lumpur laut maupun pupuk kotoran sapi) dengan nilai $16,20 \mathrm{~cm}$

Tabel 5. Interaksi antara perlakuan lumpur laut dan pupuk kotoran sapi terhadap tinggi tanaman (cm) umur 5 MST

\begin{tabular}{cc}
\hline Perlakuan & Rata-rata $(\mathrm{cm})$ \\
\hline L3K3 & $29,46 \mathrm{a}$ \\
L1K3 & $28,53 \mathrm{ab}$ \\
L2K3 & $27,73 \mathrm{ab}$ \\
L3K2 & $27,13 \mathrm{ab}$ \\
L3K1 & $26,80 \mathrm{ab}$ \\
L1K2 & $26,40 \mathrm{ab}$ \\
L2K2 & $25,93 \mathrm{bc}$ \\
L3K0 & $25,86 \mathrm{bc}$ \\
L0K3 & $25,60 \mathrm{bc}$ \\
L0K2 & $25,40 \mathrm{bc}$ \\
L2K1 & $25,30 \mathrm{bc}$ \\
L2K0 & $25,16 \mathrm{bc}$ \\
L1K1 & $23,03 \mathrm{~cd}$ \\
L1K0 & $22,73 \mathrm{~cd}$ \\
L0K1 & $21,16 \mathrm{~d}$ \\
L0K0 & $16,20 \mathrm{e}$ \\
\hline Duncan $=$ & 2.8713 .0183 .1133 .1813 .2333 .273 \\
0.05 & 3.3063 .3333 .3553 .3743 .3903 .404 \\
\hline
\end{tabular}

Keterangan: Angka-angka yang diikuti oleh huruf kecil yang tidak sama pada kolom yang sama menunjukkan berbeda nyata menurut uji Duncan pada taraf uji 0.05

Hubungan antara tinggi tanaman dengan berbagai perlakuan lumpur laut pada umur tanam 1, 2, 3, 4 dan 5 MST dapat dilihat pada Gambar 1 .

Hubungan antara tinggi tanaman dengan berbagai perlakuan pupuk kotoran sapi pada umur tanaman 1, 2, 3, 4 dan 5 MST dapat dilihat pada Gambar 2.

Tabel 6. Jumlah daun (helai) pada perlakuan lumpur laut pada umur 3 , 4, dan 5 MST

\begin{tabular}{cccc}
\hline \multirow{2}{*}{ Perlakuan } & \multicolumn{3}{c}{ Jumlah daun } \\
\cline { 2 - 4 } & $3 \mathrm{MST}$ & $4 \mathrm{MST}$ & $5 \mathrm{MST}$ \\
\hline L0 & $7,00 \mathrm{~b}$ & $8,83 \mathrm{~b}$ & $12,58 \mathrm{c}$ \\
L1 & $8,16 \mathrm{a}$ & $11,16 \mathrm{a}$ & $15,41 \mathrm{~b}$ \\
L2 & $8,41 \mathrm{a}$ & $12,33 \mathrm{a}$ & $16,66 \mathrm{ab}$ \\
L3 & $8,75 \mathrm{a}$ & $12,33 \mathrm{a}$ & $17,50 \mathrm{a}$ \\
\hline Duncan= & 1.120 & 1.384 & 1.863 \\
0.05 & 1.177 & 1.455 & 1.958 \\
& 1.214 & 1.501 & 2.020 \\
\hline
\end{tabular}

Keterangan: Angka-angka yang diikuti oleh huruf kecil yang tidak sama pada kolom yang sama menunjukkan berbeda nyata menurut uji duncan pada taraf uji 0,05 


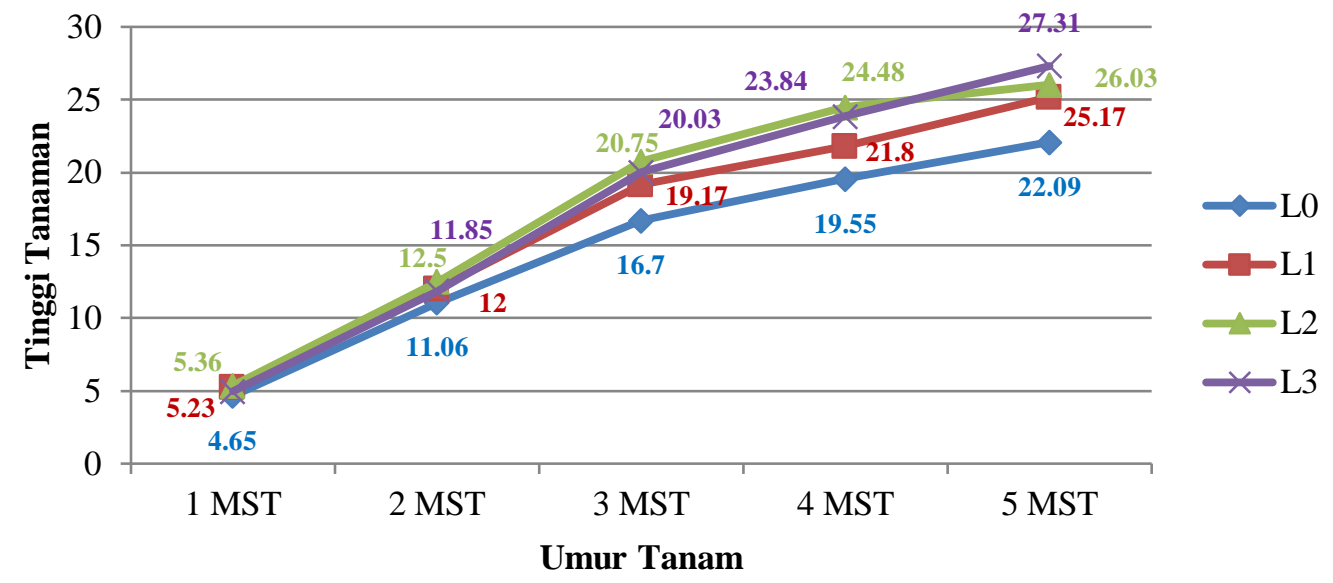

Gambar 1. Grafik hubungan antara tinggi tanaman dengan perlakuan lumpur laut pada umur tanaman 1, 2, 3, 4 dan 5 MST

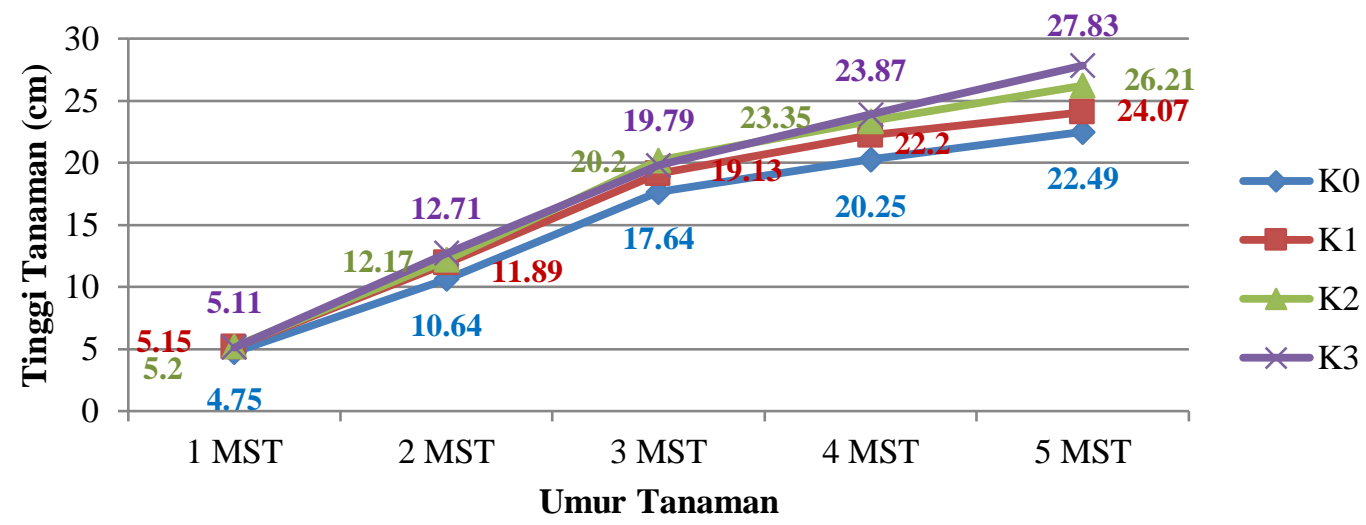

Gambar 2. Grafik hubungan antara tinggi tanaman dengan perlakuan pupuk kotoran sapi pada umur tanaman 1, 2, 3, 4 dan 5 MST

\section{Jumlah Daun}

Tabel 6 menunjukkan bahwa perlakuan lumpur laut L3 memberikan nilai tertinggi pada jumlah daun umur 3, 4 dan 5 MST. Namun pada umur tanam 3 dan 4 MST tidak berbeda nyata dengan perlakuan lumpur laut L2 dan perlakuan lumpur laut L1 sedangkan pada umur tanam 5 MST hanya tidak berbeda nyata dengan perlakuan lumpur laut L2 tetapi berbeda nyata denagan perlakuan lumpur laut (L0) yang memberikan hasil terendah.

Tabel 7 menunjukkan bahwa perlakuan pupuk kotoran sapi K3 memberikan nilai tertinggi pada jumlah daun umur 3, 4 dan 5 MST, dan ini tidak berbeda nyata dengan perlakuan pupuk kotoran sapi K1 dan K2 pada umur tanam 3 MST dan 5 MST, tetapi pada umur 4 MST berbeda nyata dengan K2. Sedangkan rata-rata nilai terendah terdapat pada umur tanam 3, 4 dan 5 MST, ditunjukkan pada K0 (kontrol tanpa pupuk kotoran sapi).
Hubungan antara jumlah daun dengan berbagai perlakuan lumpur laut pada umur tanam 1, 2, 3, 4 dan 5 MST dapat dilihat pada Gambar 3.

Hubungan antara jumlah daun dengan berbagai perlakuan pupuk kotoran sapi pada umur tanaman 1, 2, 3, 4 dan 5 MST dapat dilihat pada Gambar 4.

Tabel 7. Jumlah daun (helai) pada perlakuan pupuk kotoran sapi pada umur 3, 4, dan 5 MST

\begin{tabular}{cccc}
\hline \multirow{2}{*}{ Perlakuan } & \multicolumn{3}{c}{ Jumlah daun } \\
\cline { 2 - 4 } & $3 \mathrm{MST}$ & $4 \mathrm{MST}$ & $5 \mathrm{MST}$ \\
\hline K0 & $7,5 \mathrm{~b}$ & $10,08 \mathrm{~b}$ & $13,58 \mathrm{~b}$ \\
K1 & $8,16 \mathrm{ab}$ & $10,66 \mathrm{~b}$ & $15,41 \mathrm{ab}$ \\
K2 & $7,75 \mathrm{ab}$ & $11,50 \mathrm{ab}$ & $16,58 \mathrm{a}$ \\
K3 & $8,91 \mathrm{a}$ & $12,25 \mathrm{a}$ & $16,58 \mathrm{a}$ \\
\hline Duncan $=$ & 1.120 & 1.384 & 1.863 \\
0.05 & 1.177 & 1.455 & 1.958 \\
& 1.214 & 1.501 & 2.020
\end{tabular}

Keterangan: Angka-angka yang diikuti oleh huruf kecil yang tidak sama pada kolom yang sama menunjukkan berbeda nyata menurut uji duncan pada taraf uji 0,05 


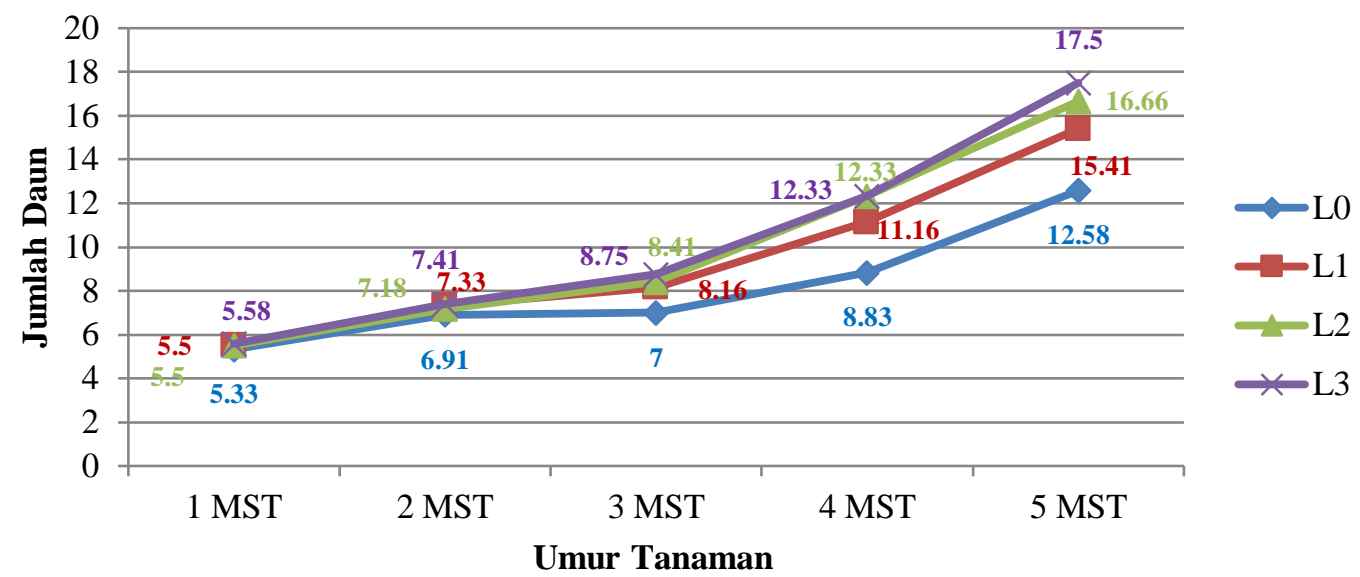

Gambar 3. Grafik hubungan antara jumlah daun dengan perlakuan lumpur laut pada umur tanaman 1, 2, 3, 4 dan 5 MST

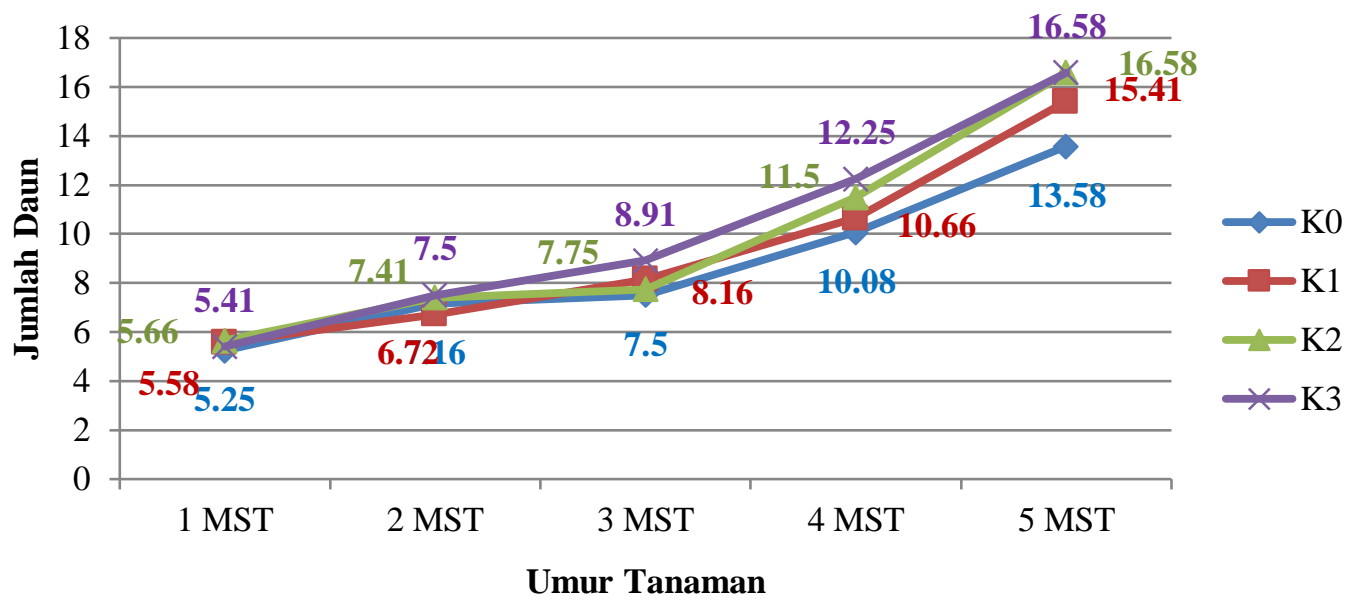

Gambar 3. Grafik hubungan antara jumlah daun dengan perlakuan pupuk kotoran sapi pada umur tanaman 1, 2, 3, 4 dan 5 MST

\section{Luas Daun}

Tabel 8. menunjukkan bahwa pada variabel pengamatan luas daun tanaman, perlakuan lumpur laut L3 memberikan nilai tertinggi yaitu $1826,5 \mathrm{~cm}^{2}$ dan tidak berbeda nyata dengan perlakuan lumpur laut L2. Sedangkan nilai terendah didapatkan pada perlakuan lumpur laut L0 yaitu $836,4 \mathrm{~cm}^{2}$.

Tabel 8. Luas daun $\left(\mathrm{cm}^{2}\right)$ pada berbagai perlakuan lumpur laut

\begin{tabular}{|c|c|}
\hline Perlakuan & Luas daun $\left(\mathrm{cm}^{2}\right)$ \\
\hline L0 & $836,4 \mathrm{c}$ \\
\hline L1 & $1327,2 \mathrm{~b}$ \\
\hline L2 & $1826,5 \mathrm{a}$ \\
\hline L3 & $1826,5 \mathrm{a}$ \\
\hline
\end{tabular}

Keterangan: Angka-angka yang diikuti oleh huruf kecil yang tidak sama pada kolom yang sama menunjukkan berbeda nyata menurut uji duncan pada taraf uji 0,05

\section{Bobot Segar Biomaasa Tanaman}

Tabel 9 menunjukkan bahwa perlakuan lumpur laut $300 \mathrm{~g}$ per $\mathrm{kg}$ tanah (L3) memberikan nilai tertinggi yaitu 126,25 g dan tidak berbeda nyata dengan perlakuan lumpur laut $200 \mathrm{~g}$ per $\mathrm{kg}$ tanah (L2). sedangkan hasil terendah di tunjukan pada perlakuan lumpur laut kontrol (L0) yaitu 45,75 g.

Tabel 9. Bobot segar biomassa tanaman (g) pada berbagai perlakuan lumpur laut

\begin{tabular}{|c|c|}
\hline Perlakuan & Bobot Segar Biomassa tanaman \\
\hline L0 & $45,75 \mathrm{c}$ \\
\hline L1 & $93,91 \mathrm{~b}$ \\
\hline L2 & $118,75 \mathrm{a}$ \\
\hline L3 & $126,25 \mathrm{a}$ \\
\hline Duncan $=0.05$ & $\begin{array}{lll}9.51 & 20.50 & 21.15\end{array}$ \\
\hline
\end{tabular}

Keterangan: Angka-angka yang diikuti oleh huruf kecil yang tidak sama pada kolom yang sama menunjukkan berbeda nyata menurut uji duncan pada taraf uji 0,05 
Tabel 10. Bobot segar biomassa tanaman (g) pada berbagai perlakuan pupuk kotoran sapi

\begin{tabular}{cc}
\hline Perlakuan & Bobot Segar Biomassa Tanaman \\
\hline K0 & $69,41 \mathrm{c}$ \\
K1 & $87,16 \mathrm{bc}$ \\
K2 & $104,75 \mathrm{~b}$ \\
K3 & $125,08 \mathrm{a}$ \\
\hline
\end{tabular}

Duncan $=0.05 \quad 19.51 \quad 20.50 \quad 21.15$

Keterangan: Angka-angka yang diikuti oleh huruf kecil yang tidak sama pada kolom yang sama menunjukkan berbeda nyata menurut uji duncan pada taraf uji 0,05

Tabel 10 menunjukkan bahwa pada perlakuan pupuk kotoran sapi $15 \mathrm{~g}$ per kg tanah (K3) memberikan nilai tertinggi pada bobot total tanaman, yaitu dengan nilai 125,08 g. dan nilai terendah ditunjukkanoleh perlakuan pupuk kotoran sapi K0/Kontrol yaitu 69,41 g.

\section{Bobot Segar Tajuk Tanaman}

Tabel 11 menunjukkan bahwa perlakuan lumpur laut (L3) meberikan nilai tertinggi yaitu 119,66 g dan tidak berbeda nyata dengan perlakuan (L2). sedangkan nilai terendah ditunjukkan pada perlakuan (L0) yaitu $42,83 \mathrm{~g}$.

Tabel 11. Bobot segar tajuk tanaman (g) pada perlakuan lumpur laut

\begin{tabular}{|c|c|}
\hline Perlakuan & Bobot tajuk tanaman $(\mathrm{g})$ \\
\hline LO & $42,83 \mathrm{c}$ \\
\hline L1 & $88,33 \mathrm{~b}$ \\
\hline L2 & $112,16 \mathrm{a}$ \\
\hline L3 & $119,66 \mathrm{a}$ \\
\hline
\end{tabular}

Keterangan: Angka-angka yang diikuti oleh huruf kecil yang tidak sama pada kolom yang sama menunjukkan berbeda nyata menurut uji duncan pada taraf uji 0,05

Tabel 12. Bobot segar tajuk tanaman (g) pada perlakuan pupuk kotoran sapi

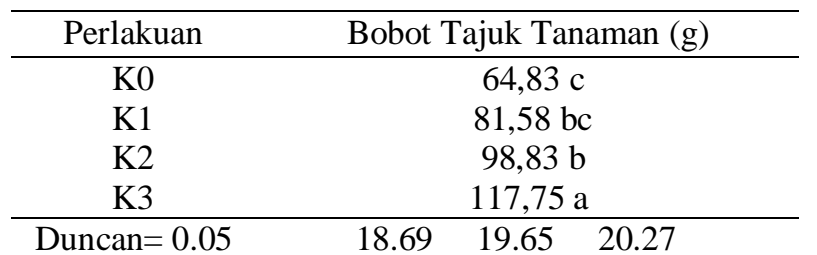

Keterangan: Angka-angka yang diikuti oleh huruf kecil yang tidak sama pada kolom yang sama menunjukkan berbeda nyata menurut uji duncan pada taraf uji 0,05

Tabel 12 menunjukkan bahwa perlakuan pupuk kotoran sapi (K3) memberikan nilai tertinggi pada bobot tajuk tanaman. sedangkan nilai terendah ditunjukkan pada perlakuan K0/Kontrol yaitu 64,83 g.

\section{Bobot Segar Akar Tanaman}

Tabel 13 menunjukkan bahwa perlakuan lumpur laut (L2) meberikan nilai tertinggi yaitu $6,91 \mathrm{~g}$ dan tidak berbeda nyata dengan perlakuan (L3). Sedangkan nilai terendah ditunjukkan pada perlakuan (L0) yaitu 4,25 g.

Tabel 13. Bobot segar akar tanaman (g) pada perlakuan lumpur laut

\begin{tabular}{|c|c|}
\hline Perlakuan & Bobot Segar Akar Tanaman (g) \\
\hline L0 & $4,25 \mathrm{~b}$ \\
\hline L1 & $5,41 \mathrm{ab}$ \\
\hline L2 & $6,91 \mathrm{a}$ \\
\hline L3 & $6,58 \mathrm{a}$ \\
\hline
\end{tabular}

Keterangan: Angka-angka yang diikuti oleh huruf kecil yang tidak sama pada kolom yang sama menunjukkan berbeda nyata menurut uji duncan pada taraf uji 0,05

\section{Pembahasan}

\section{Pengaruh perlakuan lumpur aut}

Pemakaian lumpur laut dan pupuk kotoran sapi pada tanah ultisol dimaksudkan untuk penyediaan unsur hara secara organik bagi pertumbuhan, perkembangan dan produksi tanaman sawi sendok di tanah Ultisol. Pada penelitian ini, kombinasi perlakuan lumpur laut dan pupuk kotoran sapi memberikan pengaruh baik secara tunggal, adanya interaksi maupun tidak berpengaruh atau tidak nyata. Perlakuan Lumpur laut berpengaruh terhadap pertumbuhan, perkembangan dan produksi yaitu bagian tajuk tanaman (tinggi tanaman, jumlah daun dan luas daun), dan bagian akar tanaman (Tabel 1).

Variabel tinggi tanaman perlakuan lumpur laut pada minggu 1 dan 2 MST, dan perlakuan pupuk kotoran sapi minggu 1 setelah tanam tidak memberikan pengaruh (Tabel 2 dan Tabel 3). Ini dapat dijelaskan bahwa pada minggu pertama dan kedua tanaman sawi sendok ada dalam keadaan recovery atau daya sembuh akibat pindah tanam dan berada pada tahap awal pertumbuhan vegetatif, juga belum memiliki banyak akar untuk menyerap hara. Terdapat pengaruh faktor tunggal perlakuan lumpur laut pada variabel tinggi tanaman 3 MST dan yang nilainya tertinggi, yaitu 20.75 $\mathrm{cm}$ pada perlakuan L2 (200 g L per $\mathrm{kg}$ ), dan tidak berbeda nyata dengan L1 dan L3. Pada minggu ketiga pertumbuhan vegetatif, tanaman sawi sendok sudah beradaptasi dengan baik dan akar tanaman telah melakukan fungsinya untuk penyerapan unsur hara. Menurut Matulessy et al., (2015), aplikasi lumpur laut dapat meningkatkan $\mathrm{pH}$ dan menurunkan konsentrasi kelarutan $\mathrm{Al}$ pada tanah ultisol, sehingga unsur hara tersedia bagi tanaman dan dapat diserap untuk pertumbuhan tanaman sawi sendok.

Untuk variabel pengamatan jumlah daun, berdasarkan hasil analisis data tidak terdapat interaksi pada semua minggu setelah tanam, tetapi terjadi pengaruh faktor tunggal pada 3,4 dan 5 MST. 
Sedangkan pada 1 dan 2 MST, baik perlakuan lumpur laut maupun pupuk kandang tidak berpengaruh nyata (Tabel 1). Pada 3 dan 4 MST untuk variabel pengamatan jumlah daun, perlakuan lumpur laut (dosis L1, L2 dan L3) memberikan pengaruh yang sama dan tidak terdapat perbedaan pada ketiga dosis ini tetapi berbeda nyata dengan kontrol. Pada 5 MST, perlakuan lumpur laut L3 (300 g L per $\mathrm{kg}$ tanah) jumlah daun adalah 17.50 helai. Hasil ini tidak berbeda nyata dengan perlakuan L2 (200 g L per kg tanah), yaitu 16.66. Hasil analisis Matulessy et al., (2018) lumpur laut dari desa Tulehu mengandung unsur hara yang dibutuhkan tanaman dalam menunjang pertumbuhannya; terutama pengaruhnya terhadap $\mathrm{pH}, \mathrm{P}, \mathrm{KTK}$, jumlah dari kationkation basa dapat ditukar dan menurunkan $\mathrm{Al}_{\mathrm{dd}}$.

Variabel pengamatan luas daun (Tabel 1) hanya dipengaruhi oleh perlakuan lumpur laut secara tunggal, sedangkan perlakuan pupuk kotoran sapi dan interaksinya tidak nyata. Pengaruh lumpur laut yang baik dan sangat nyata pada luas daun (Tabel 8) terdapat pada perlakuan lumpur laut $300 \mathrm{~g}$ per $\mathrm{kg}$ tanah ultisol (L3) serta perlakuan lumpur laut $200 \mathrm{~g}$ per $\mathrm{kg}$ tanah ultisol (L2) dengan luas daun 1826,5 $\mathrm{cm}^{2}$. Dalam lumpur laut unsur hara makro, khususnya $\mathrm{N}, \mathrm{P}$ dan $\mathrm{K}$, yang sangat dibutuhkan untuk pertumbuhan vegetatif terdapat dalam jumlah yang tersedia bagi tanaman sawi sendok, yaitu $\mathrm{N}=0.04$ me. $100 \mathrm{~g}^{-1}, \mathrm{~K}=1.01 \mathrm{me}^{100 \mathrm{~g}^{-1}}$ dan $\mathrm{P}=6.99$ ppm (Matulessy et al., 2018).

Terdapat pengaruh faktor tunggal lumpur laut dan pupuk kandang terhadap bobot segar biomassa dan bobot segar tajuk, tetapi tidak terdapat interaksi diantara kedua perlakuan yang dicobakan (Tabel 1). Perlakuan lumpur laut berpengaruh sangat nyata terhadap kedua variabel ini. Varibel pengamatan ini adalah variabel produksi, dan lumpur laut maupun pupuk kandang dapat menyumbang unsur hara yang dibutuhkan oleh tanaman sawi sendok. Untuk berat segar biomassa yang menunjukkan respon yang sangat baik terdapat pada perlakuan lumpur laut $300 \mathrm{~g}$ per $\mathrm{kg}$ tanah ultisol (L3), yaitu dengan berat bimassa $125,08 \mathrm{~g}$ dan perlakuan lumpur laut $200 \mathrm{~g}$ per $\mathrm{kg}$ tanah ultisol (L2), yaitu 104,75 g. Kedua perlakuan ini bedasarkan hasil analisis keragaman memiliki notasi yang sama (Tabel 9). Tetapi ini berbeda dengan perlakuan lumpur laut $100 \mathrm{~g}$ per $\mathrm{kg}$ tanah ultisol (L1) dan kontrol. Demikian halnya dengan berat segar tajuk tanaman sawi sendok (Tabel 11), perlakuan lumpur laut $300 \mathrm{~g}$ per $\mathrm{kg}$ tanah ultisol (L3), yaitu $112,16 \mathrm{~g}$, dan perlakuan lumpur laut $200 \mathrm{~g}$ per $\mathrm{kg}$ tanah ultisol (L2), yaitu 119,66 g, tetapi berbeda dengan perlakuan lumpur laut $100 \mathrm{~g}$ per $\mathrm{kg}$ tanah ultisol (L1) dan kontrol. Untuk variabel pengamatan berat segar akar (Tabel 1), hanya perlakuan lumpur laut yang memberikan pengaruh nyata. Hasil analisis keragaman (Tabel 13) menunjukkan bahwa perlakuan L2 (lumpur laut $200 \mathrm{~g}$ per $\mathrm{kg}$ tanah ultisol) memberikan berat akar $6,91 \mathrm{~g}$ dan tidak berbeda dengan L3 (lumpur laut $300 \mathrm{~g}$ per $\mathrm{kg}$ tanah ultisol), yaitu seberat 6,58. Tetapi ini berbeda dengan perlakuan lumpur laut $100 \mathrm{~g}$ per $\mathrm{kg}$ tanah ultisol (L1) dan kontrol.

\section{Perlakuan pupuk kotoran sapi}

Tabel 1 menunjukkanbahwa perlakuan pupuk kotoran sapi berpengaruh nyata terhadap tinggi tanaman 3 MST dan jumlah daun pada 4 MST. Pengaruh sangat nyata terdapat pada tinggi tanaman $(2,4$ dan 5 MST), jumlah daun (3, dan 5 MST), bobot segar biomassa tanaman dan bobot segar tajuk tanaman. Namun, perlakuan itu berpengaruh tidak nyata terhadap variabel tinggi tanaman (1 MST), jumlah daun (1 dan 2 MST), luas daun dan bobot akar tanaman.

Berdasarkan hasil analisi keragaman pada variabel tinggi tanaman (Tabel 3), perlakuan pupuk kotoran sapi menunjukkanbahwa pada minggu kedua setelah tanam untuk K1, K2 dan K2 mempunyai notasi yang sama artinya tidak berbeda. Sedangkan pada 3 MST K2 (pupuk kotoran sapi $10 \mathrm{~g}$ per $\mathrm{kg}$ tanah ultisol) memiliki angka yang tinggi, yaitu $20.20 \mathrm{~cm}$, juga K3 (pupuk kotoran sapi15 g per $\mathrm{kg}$ tanah ultisol). Tetapi keduanya memberikan pengaruh yang sama.

Variabel jumlah daun, perlakuan pupuk kotoran sapi pada 3 dan MST menunjukkanbahwa K3 (15 g per $\mathrm{kg}$ tanah ultisol) memberikan nilai tertinggi, tetapi tidak berbeda dengan perlakuan pupuk kotoran sapi $10 \mathrm{~g}$ per $\mathrm{kg}$ tanah ultisol. Sedangkan untuk pengamatan jumlah daun pada 5 MST, perlakuan K2 dan K3 memberikan hasil yang terbaik dan sama, yaitu 16,58 helai.

Parameter produksi tanaman sawi sendok adalah variabel pengamatan berat segar biomassa dan berat segar tajuk. Perlakuan K3 (pupuk kotoran sapi $15 \mathrm{~g}$ per $\mathrm{kg}$ tanah ultisol) memberikan pertambahan berat yang signifikan dengan perlakuan K2, K1 dan control. Dari semua pengaruh pupuk kotoran sapi pada beberapa parameter pengamatan dapat dijelaskan bahwa semakian banyak pupuk yang diberikan akan semakin banyak pula unsur hara yang diterima oleh tanaman. Selain itu, pemberian pupuk kotoran sapi dengan kandungan unsur hara yang diperlukan tersedia untuk tanaman sawi sehingga mampu meningkatkan pertumbuhan dan hasil tanaman sawi.

Menurut Ohorella (2012), pertumbuhan tanaman sawi sendok dapat terjadi baik karena pupuk organik kotoran sapi menyebabkan terdorongnya atau terpacunya sel di ujung batang untuk segera mengadakan pembelahan dan pembesaran sel terutama di daerah meristematis, sehingga mempercepat pertambahan tinggi tanaman karena pupuk ini dapat meningkatkan bahan organik tanah dan ketersediaan unsur hara sehingga berpengaruh terhadap tinggi tanaman, yang selanjutnya juga berkontribusi dalam peningkatan jumlah daun, bobot total tanaman dan bobot tajuk tanaman.

Pupuk kandang mengandung unsur hara $\mathrm{N}$ yang berfungsi untuk pembentukan asimilat, terutama karbohidrat dan protein, serta berfungsi sebagai bahan penyusun klorofil yang dibutuhkan dalam proses fotosintesis. Adanya $\mathrm{N}$ yang cukup pada tanaman akan memperlancar proses pembelahan sel karena $\mathrm{N}$ mempunyai peranan utama untuk merangsang pertumbuhan secara keseluruhan, khususnya pertumbuhan batang, sehingga memicu pertumbuhan tinggi tanaman, jumlah daun dan 
bobot tanaman (Syarif, 1985 dalam Riyawati, 2012). Selain itu pupuk kandang juga dapat meningkatkan kandungan unsur hara dan daya ikat air tanah, sehingga akar tanaman dapat lebih mudah menyerap nutrisi. Pemberian pupuk kandang dapat meningkatkan bahan organik dalam tanah sehingga pertumbuhan dan produksi tanaman lebih optimal (Azizah et al., 2016). Menurut Irfan et al., (2017), dalam pupuk kotoran sapi, unsur $\mathrm{N}, \mathrm{P}$, dan $\mathrm{K}$ terdapat dalam jumlah yang sedikit, yaitu $0.4,0.2$ dan $0.1 \mathrm{ppm}$ sehingga dalam menyumbangkan unsur hara bagi tanaman juga sangat sedikit.

\section{Interaksi perlakuan lumpur laut dan pupuk kotoran sapi}

Interaksi antara perlakuan lumpur laut dan pupuk kotoran sapi hanya berpengaruh pada tinggi tanaman pada 4 dan 5 MST. Sedangkan terhadap variabelvariabel pengamatan yang lain tidak terdapat pengaruh interaksi. Untuk tinggi tanaman 4 MST, kombinasi perlakuan L2K2 (lumpur laut $200 \mathrm{~g}$ per $\mathrm{kg}$ dan pupuk kotoran sapi $10 \mathrm{~g}$ per $\mathrm{kg}$ tanah ultisol) memberikan nilai tertinggi, yaitu $26.26 \mathrm{~cm}$, tetapi tidak berbeda nyata dengan perlakuan L3K1, L2K1, L3K2, L2K3, L3K3 dan L0K3. Sedangkan untuk tinggi tanaman 5 MST, kombinasi perlakuan terbaik adalah L3K3 (lumpur laut $300 \mathrm{~g}$ per $\mathrm{kg}$ tanah dan pupuk kotoran sapi $15 \mathrm{~g}$ per $\mathrm{kg}$ tanah) dengan tinggi mencapai $29.46 \mathrm{~cm}$, tetapi tidak berbeda nyata dengan kombinasi perlakuan L1K3, L2K3, L3K2, L3K1 dan L1K2.

Hasil penelitian menunjukkanbahwa terjadinya interaksi antara perlakuan lumpur laut dan pupuk kotoran sapi, karena adanya sinergisitas atau saling menunjang dalam menyumbangkan unsur hara bagi tanaman sawi sendok dan pada gilirannya memberikan pengaruh pertumbuhan tinggi tanaman, danmenyebabkan terjadinnya perbedaan pertumbuhan pada variabel tersebut.

\section{KESIMPULAN}

Dari hasil peneoitian ini dapat disimpulkan sebagai berikut:

1. Perlakuan lumpur laut berpengaruh terhadap pertumbuhan tanaman sawi, yaitu perlakuan $200 \mathrm{~g}$ per $\mathrm{kg}$ tanah memberikan nilai tertinggi pada tinggi tanaman 3 MST dan 4 MST, juga bobot akar tanaman. Sedangkan lumpur laut $300 \mathrm{~g}$ per $\mathrm{kg}$ tanah memberikan nilai tertinggi pada tinggi tanaman 5 MST, jumlah daun, luas daun, bobot total tanaman, bobot tajuk tanaman, tetapi tidak berbeda nyata dengan lumpur laut $200 \mathrm{~g}$ per $\mathrm{kg}$ tanah.

2. Perlakuan pupuk kotoran sapi berpengaruh terhadap pertumbuhan tanaman sawi, yaitu perlakuan $15 \mathrm{~g}$ per $\mathrm{kg}$ tanah memberikan nilai tertinggi pada tinggi tanaman, jumlah daun, bobot total tanamn dan bobot tajuk tanaman.

3. Kombinasi perlakuan lumpur laut $200 \mathrm{~g}$ per $\mathrm{kg}$ tanah dan pupuk kotoran sapi $10 \mathrm{~g}$ per $\mathrm{kg}$ tanah memberikan nilai tertinggi pada tinggi tanaman umur 4 MST. Sedangkan perlakuan lumpur laut 300 $\mathrm{g}$ per $\mathrm{kg}$ tanah dan pupuk kotoran sapi $15 \mathrm{~g}$ per $\mathrm{kg}$ tanah memberikan nilai tertinggi pada tinggi tanaman umur 5 MST.

\section{DAFTAR PUSTAKA}

Azizah, N., G. Haryono dan Tujiyanta. 2016. Respon macam pupuk organik dan macam mulsa terhadap hasil tanaman sawi caisin (Brassica juncea L.) var. Tosakan. Vigor, Jurnal Ilmu Pertanian Tropika dan Subtropika 1(1): 44-51. DOI: 10.31002/vigor.v1i1.316

Badan Pusat Statistik dan Direktorat Jenderal Hortikultura. 2015. Statistik Produksi Hortikultura Tahun 2014. Badan Pusat Statistik dan Direktorat Jenderal Hortikultura, Kementrian Pertanian, Jakarta.

Endriani. 2010. Sifat fisika dan kadar air tanah Ultisol akibat penerapan sistem olah tanah konservasi. Jurnal Hidrolitan. Jurnal Hidrolitan 1(1): 26-34.

Irfan., Rasdiansyah dan M. Munadi (2017), Kualitas bokasi dari kotoran berbagai jenis hewan. Jurnal Teknologi dan Industri Pertanian Indonesia 9(1): 23-27. DOI: 10.17969/jtipi.v9i1. 5976

Kurniadi, A. 1996. Sayuran yang Digemari. Harian Suara Tani. Jakarta.

Matulessy. F., T. Wardiyati, Syekhfani, and N. Aini. 2015. Effects of application of marine mud and manure on growth and yield of Capsicum annum L on an Ultisol Maluku. Journal of Degraded and Mining Land Management 2(4): 391-396. DOI: $10.15243 / \mathrm{jdmlm} .2015 .024 .391$.

Matulessy F., M.L. Hehanussa, dan I.J. Lawalata. 2018. Identifikasi dan Analisis Kandungan Unsur Dalam Lumpur Laut Pada Tiga Lokasi di Pulau Ambon Sebagai Hara Tanaman, Memperbaiki Sifat Kimia Dan Biologi Tanah Ultisol. Laporan Penelitian Dasar Unggulan Perguruan Tinggi, Universitas Pattimura, Ambon.

Ohorella, Z. 2012. Pengaruh dosis pupuk organik cair (POC) kotoran sapi terhadap pertumbuhan dan produksi tanaman sawi hijau (Brassica sinensis L.). Jurnal Agroforestri 7(1): 43-39.

Riyawati. 2012. Pengaruh Residu Pupuk Kandang Ayam dan Sapi pada Pertumbuhan Sawi (Brassica juncea L. ) di Media Gambut. Skripsi. Program Studi Agroteknologi, Fakultas Pertanian dan Peternakan, Universitas Islam Negeri Sultan Syarif Kasim, Riau.

Sutejo dan Kartasapoetra. 2002. Pengantar Ilmu Tanah. Jakarta: Rineka Cipta.

Suryadi. 1995. Pemanfaatan Lumpur Laut dan Kapur untuk Memperbaiki Kesuburan Tanah Gambut untuk Budidaya Kedele (Glycine max L. Merril), p.1-22. Makalah pada Pertemuan Bidang Ilmu Pertanian se BKS Barat, Pontianak. 